\title{
Cotisations centrales FMH pour 2007
}

Suite à une proposition spontanée issue de ses propres rangs (et non à une proposition du Comité central ou du président!) la Chambre médicale a pris, lors de sa séance extraordinaire des 14 et 15 décembre 2006, les décisions suivantes affectant le montant de la cotisation centrale 2007:

1. augmentation de Fr. 100.- de la cotisation de base FMH (échelonnée en fonction des catégories de membres), limitée à 2007 et destinée à compenser le déficit budgétaire;

2. crédit spécial de Fr. 25.- (échelonné en fonction des catégories de membres) pour la création d'une carte de professionnel de santé (CPS).

Les cotisations centrales 2007 se composent donc désormais* comme suit:

\begin{tabular}{|c|c|c|c|c|c|c|}
\hline $\begin{array}{l}\text { Catégorie } \\
\text { de membres }\end{array}$ & $\begin{array}{l}\text { Cotisation de } \\
\text { base FMH (nouveau } \\
\text { montant)* }\end{array}$ & $\begin{array}{l}\text { Contribution } \\
\text { spéciale HIN }\end{array}$ & $\begin{array}{l}\text { Contribution } \\
\text { spéciale Assistanat } \\
\text { au cabinet }\end{array}$ & $\begin{array}{l}\text { Contribution } \\
\text { spéciale Newlndex }\end{array}$ & $\begin{array}{l}\text { Contribution } \\
\text { spéciale CPS* }\end{array}$ & Total \\
\hline 1 et 2 & 630.- (530.-+100.-) & 35.- & $25 .-$ & 45.- & 25.- & 760.- \\
\hline 3 & 315.-(265.-+50.-) & 35.- & 25.- & $0 .-$ & 12.- & 387.- \\
\hline 4 & 315.- (265.-+50.-) & 0.- & 25.- & $0 .-$ & 12.- & 352.- \\
\hline 5 et 6 & 157.- (132.-+25.-) & $0 .-$ & $0 .-$ & $0 .-$ & 6.- & 163.- \\
\hline
\end{tabular}

*Ces augmentations deviennent effectives à l'échéance du délai référendaire de 60 jours suivant la publication du procès-verbal de la Chambre médicale extraordinaire (art. 24, al. 2 des statuts de la FMH). 